\title{
Advocacy in Action: a Comprehensive Student-Led Proactive Outreach to Patients at Highest Risk
}

\author{
Rebecca S. Goldstein, M.P.H. ${ }^{7}$ (D) , Alyssa R. Greenhouse, B.A. ${ }^{7}$, Anjali Om, B.A. ${ }^{7}$, \\ Carson R. Ward, B.S. ${ }^{7}$, Leslie Marshburn, M.P.H., M.B.A. ${ }^{2}$, Cinnamon D. Bradley, M.D. ${ }^{3}$, \\ Tracey L. Henry, MD, M.P.H., M.S. ${ }^{4}$, and Maura George, M.D. ${ }^{4}$
}

'Emory University School of Medicine, Atlanta, GA, USA; ${ }^{2}$ Grady Health System, Atlanta, GA, USA; ${ }^{3}$ Department of Medicine, Morehouse School of Medicine, Atlanta, GA, USA; ${ }^{4}$ Department of Medicine, Emory University School of Medicine, Atlanta, GA, USA.

INTRODUCTION: COVID-19 disrupted access to critical healthcare and resources for many, especially affecting patients at safety-net hospitals who rely on regular care for multiple complex conditions. Students realized they could support patients from the sidelines by helping navigate abrupt healthcare changes and proactively addressing needs at home.

AIM: To comprehensively identify and meet the clinical and social needs of Atlanta, Georgia's patients at highest risk, left without their usual access to healthcare, through proactive telephonic outreach.

SETTING AND PATIENTS: Medical and Physician's Assistant students from Emory and Morehouse Schools of Medicine partnered with Grady Health System, Atlanta's safety-net hospital. Artificial intelligence prioritized over 15,000 patients by risk of morbidity and mortality from COVID-19.

PROGRAM DESCRIPTION: In this novel program, students performed telephonic outreach to thousands of patients at highest risk of poor outcomes from COVID19. Students used a custom REDCap form that served as both a call script and data collection tool. It provided stepby-step guidance to (1) screen for COVID-19 and educate on prevention; (2) help patients navigate health system changes to fill gaps in care; and (3) identify and address social needs. Based on patients' responses, the form prompted tailored reminders for next steps and connections to medical and social resources.

PROGRAM EVALUATION: In the program's first 16 months, students made 7,988 calls, of which 3,354 were answered. Over half (53\%) of patients had at least one need requiring action: $48 \%$ health and $16 \%$ social.

DISCUSSION: This proactive, novel initiative identified substantial clinical and social need among patients at highest risk for poor outcomes and filled a pressing health system gap exacerbated by COVID-19. Simultaneously, interprofessional students gained applied exposure to health systems sciences. This program can serve as a model for rapid, cost-effective, high-yield outreach to promote patient health at home both during and beyond the pandemic.

KEY WORDS: safety-net providers; COVID-19; pandemics; students, medical; delivery of health care.

Received April 13, 2021

Accepted December 8, 2021

Published online March 1, 2022
J Gen Intern Med 37(11):2661-8 DOI: $10.1007 / \mathrm{s} 11606-021-07319-\mathrm{x}$

(c) The Author(s) under exclusive licence to Society of General Internal Medicine 2021

\section{INTRODUCTION}

In the COVID-19 pandemic, many patients lack customary access to the critical healthcare and social resources they need. Measures such as physical distancing, stay-at-home orders, ${ }^{1,2}$ public transportation reductions, ${ }^{3}$ and cancelations of inperson appointments and procedures ${ }^{4-6}$ imposed unprecedented barriers to care.

Grady Health System (Grady) in Atlanta, Georgia, serves patients from all demographics throughout the metro Atlanta area, but as a safety net hospital, its patients are often resourcepoor and challenged by health disparities with multiple unmet social needs. Healthcare gaps already prevalent were severely exacerbated by COVID-19, especially for patients who relied on regular health maintenance for their multiple complex comorbidities. With disrupted and reduced healthcare contact, patients face additional increased risk of complications from their chronic conditions. ${ }^{7-9}$

While patients were forced to navigate a new and challenging healthcare landscape, health professional students were removed from clinical rotations. ${ }^{10}$ From the sidelines, students recognized the gap in care created by COVID-19 and the role they could fill: aiding patients in navigating the abrupt changes to the healthcare system and proactively addressing their health concerns at home.

A collaboration between Grady, Emory University School of Medicine (Emory), and Morehouse School of Medicine (Morehouse) formed. Volunteer medical students developed a program to perform comprehensive outreach to thousands of Atlanta's citizens at highest risk of poor outcomes if they were to become sick with COVID-19. The goals of this intervention were to:

1. Screen for COVID-19 symptoms, and educate patients on preventative strategies to protect themselves and their communities, 
2. Support patients in navigating the healthcare system during the pandemic, and

3. Identify patients' social needs and resources to address them.

\section{METHODS}

\section{Setting and Target Population}

Grady is Atlanta's safety net hospital, Georgia's largest hospital, and the nation's fifth-largest public hospital, serving nearly half a million people annually. ${ }^{11}$ Grady partnered with Jvion, ${ }^{12}$ an Atlanta-based prescriptive analytics company, who utilized clinical artificial intelligence to develop a risk calculation incorporating clinical data, socioeconomic data, and used a parallel target of poor outcomes from influenza viral infections to triangulate Grady's patients that would be at highest risk of poor outcomes from COVID-19 if they were to contract SARS-CoV-2 (Appendix 1).

\section{Program Development}

In partnership with the Executive Director of Grady's Department of Strategy and Population Health and an Emory physician faculty advisor, medical students created an integrated tool for callers to use both as a script to facilitate conversations with patients and for data collection to track patient needs (Supplemental Exhibit 1). Students utilized REDCap, a secure, web-based software platform designed to support data capture for research studies, to develop and operationalize this tool. ${ }^{13,14}$

Goals of the tool were to develop (1) questions and prompts that were comprehensive in addressing patients' medical and social needs, and (2) an interactive script for students to conduct seamless, structured calls with skip and branching logic to accommodate the flexible, varied nature of each call. As callers recorded patients' responses, the form provided integrated prompts specific to each answer, allowing students to ask only the relevant follow-up questions and to offer tailored advice. The form included novel questions designed specifically to understand Grady's patients' needs during the pandemic, the standardized Patient Health Questionnaire (PHQ)-2 ${ }^{15}$ and PHQ-9, ${ }^{16}$ and questions similar to standard social needs screening tools. ${ }^{17}$

All original volunteers attended a required virtual training session; students who joined later have been trained by watching recordings of these sessions. To document outreach calls in Epic, Grady's electronic medical record (EMR), student volunteers were provided expanded capabilities beyond the standard student access facilitated by the hospital's administrative, legal, and EMR teams.

Program development began March 24, 2020. Training sessions occurred April 1 and 10, 2020, and were recorded for future participants. Calls began April 15, 2020, and are currently ongoing.

\section{Call Process}

1. Call sign-up: Students signed up to call patients using a HIPAA-compliant platform allowing for real-time, shared edits. Calls were made to patients in order of descending risk score.

2. Chart review: Before calling, students preliminarily reviewed the patient's EMR, noting recent telehealth encounters, past hospital or clinic notes, medications, and problems. Patients who were deceased, were currently in a hospital or skilled nursing facility, or had an outpatient or telehealth appointment in the preceding 5 days were excluded. For eligible patients, students documented relevant medical history in REDCap for easy recall during the conversation.

3. Outreach call initiation: Students called patients using Doximity, ${ }^{18}$ displaying the main hospital phone number. Students attempted to call each eligible patient three times over a two-day period before considering the call unsuccessful. Calls were made between 9:00AM and 8:00PM, seven days a week.

4. Outreach conversation: During calls, students followed the REDCap form for step-by-step guidance to (1) screen the patient for COVID-19 symptoms, (2) ask about their general health and medical concerns, (3) assess whether the patient needed medications or supplies (example in Fig. 1), and (4) ask about social impacts and support needed. Based on responses, the form systematically prompted callers to provide important health reminders and produced referrals tailored to the patient's specific needs. These included guidance on physical distancing as well as connections and referrals to health resources (e.g., medications, telehealth appointments, mental health) and social resources (e.g., food banks, grocery support, rent and utility assistance, housing services). The call script provided language instructing the student to conduct three-way calls for additional support such as to the Grady Nurse Advice Line for urgent health crises and to the Georgia Crisis and Access Line (GCAL) ${ }^{19}$ for acute mental health support. Specifically, students called GCAL if the patient's PHQ9 score was $\geq 15$ or if the patient endorsed the final question on the PHQ9 ("thoughts that you would be better off dead, or thoughts of hurting yourself in some way"). Additionally, referral suggestions to a variety of mental health services beyond GCAL (e.g., Grady's Behavioral Health Outpatient Center, a primary care physician for a referral to Grady Behavioral Health, and Georgia's COVID-19 Emotional Support Line) appear if the student denoted that the patient expressed anxiety or other mood disturbances. Additionally, students offered patients enrollment in MyChart, Grady's online patient portal. Students ended 


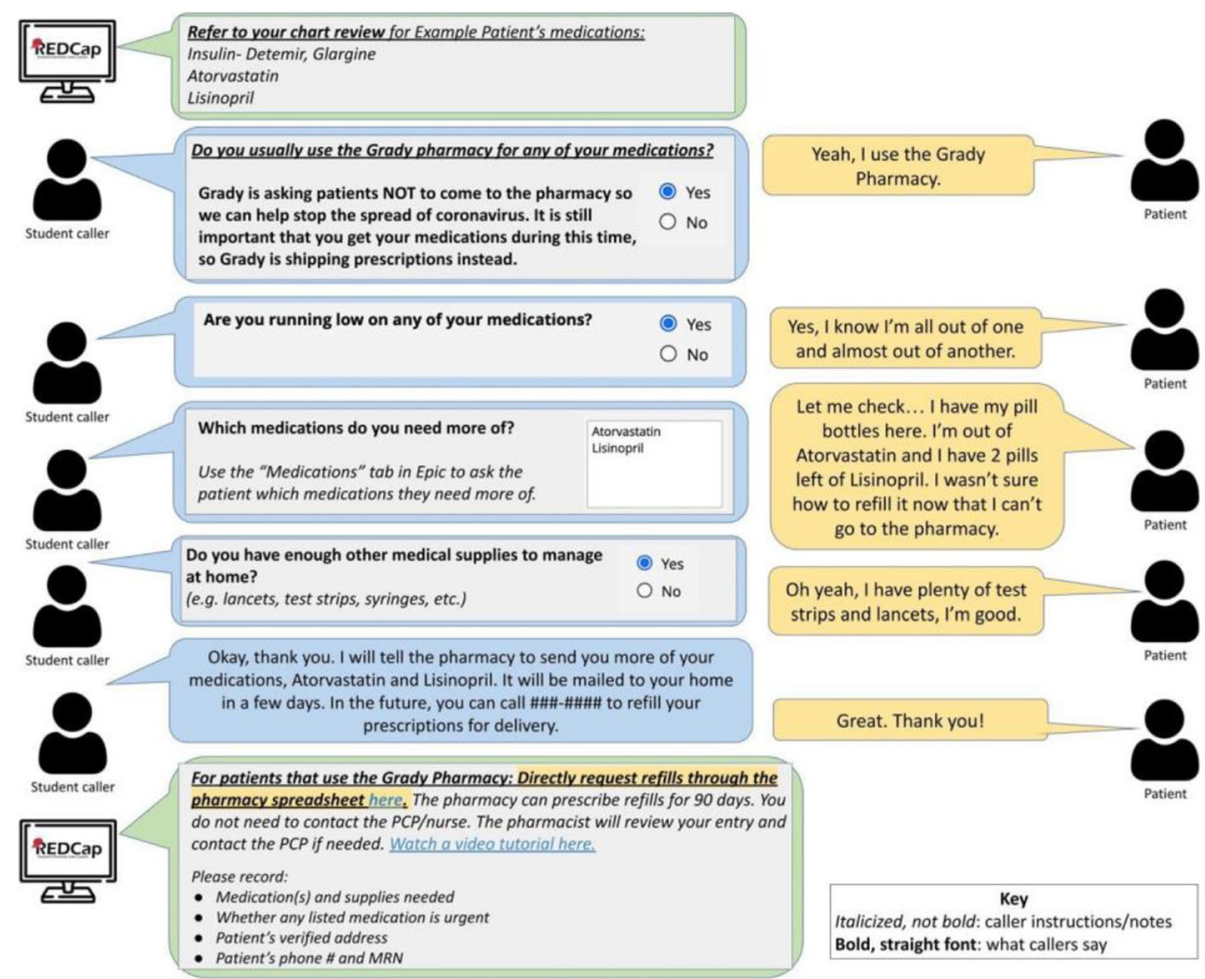

Figure 1 Excerpt of telephone conversation between a student caller and patient. The REDCap script prompts the caller to take specific action to address a medical need

each call by soliciting questions from the patient and summarizing the discussion.

5. Post-call follow-up: Students used a custom checklist within the REDCap form to document the needs ascertained during the call. Based on the patient's needs, students would contact the Grady Pharmacy to have prescription refills mailed to the patient for free through an expedited partnership, contact the patient's providers about health concerns, schedule telehealth appointments, and connect patients with social resources. Students then documented the discussion in the EMR and could route the note or otherwise alert the patient's care team about any concerns. Some patients later received follow-up calls.

\section{Student Support and Oversight}

The REDCap form contained instructions and links throughout, referring students to the most relevant resources at each stage of the call and helping students navigate common needs that a patient may have. Students developed additional resources including a caller training manual, a Patient Resources Encyclopedia, and an EMR documentation guide. Students also established an interactive discussion board through GroupMe a free group messaging app, to pose and answer each other's general questions, share de-identified experiences, receive real-time faculty support, and plan for HIPAAcompliant follow-up with faculty (e.g., through a phone call). An interdisciplinary team of attending physicians from
Grady's Primary Care Center, a pharmacist, and a social worker were available to answer student questions throughout the program. Finally, student peer reviewers monitored call quality and appropriate follow-up. Together, these support systems provided initiative-specific protocol guidance and helped students make calls effectively despite varied experience and comfort levels, all with decentralized supervision.

This public health practice was determined to be exempt from Emory's Institutional Review Board.

\section{RESULTS}

We trained an initial 253 volunteer students from four programs at two academic institutions in Atlanta: 129 medical and 16 Physician's Assistant (PA) students from Emory and 79 medical and 29 PA students from Morehouse (Table 1). All medical students were in their third or fourth year, and all PA students were in their second year. Additional students have been trained since this time.

Jvion produced a list of 15,011 patients, $51 \%$ female, and with a median age of 66 (range: 1 to 113 ; IQR 57, 75), (Table 1). Of these, 1,882 patients were called through a separate cancer care initiative and thus excluded (Fig. 2). Student volunteers began calling the remaining 13,129 patients. An additional 1,509 patients were excluded because they were deceased, hospitalized, had recent healthcare contact, were in a nursing home, receiving hospice care, or had invalid contact information. 
Table 1 Patient and student caller demographics

\begin{tabular}{ll}
\hline \hline Patients & \\
\hline Total patients on Jvion list (n) & 15,011 \\
Total included patients (n) & 13,169 \\
Median patient age of Jvion list, median (IQR) & $66(57,75)$ \\
Patient gender: total female patients & $6,760(51 \%)$ \\
Patient race (among 7,988 attempted calls) & $\mathrm{n}(\%)$ \\
African American & $5,882(83.3 \%)$ \\
Hispanic & $157(2.2 \%)$ \\
White & $479(6.8 \%)$ \\
Asian & $21(0.3 \%)$ \\
American Indian and Alaskan Native & $8(0.1 \%)$ \\
Native Hawaiian and Other Pacific & $8(0.1 \%)$ \\
Islander & $10(0.14 \%)$ \\
Multi-Racial & $491(7.0 \%)$ \\
Unknown & \\
& \\
\hline Students volunteers involved during program's first 16 months \\
Total initial MD students trained & 208 \\
Emory University School of Medicine & 129 \\
MD students (third and fourth year) & \\
Morehouse School of Medicine MD & 79 \\
students (third and fourth year) & 45 \\
Total initial PA students trained & 16 \\
Emory University School of Medicine PA & \\
students (second year) & 29 \\
Morehouse School of Medicine PA & \\
students (second year) & 253 \\
Total students trained initially & \\
Total student who made calls & \\
\hline
\end{tabular}

In the program's first 16 months, 273 students each attempted a median of 30 calls (range: 1 to 116; IQR 18, 41). Collectively, students have made 7,988 calls to date (Fig. 2). Of these, 3,354 were answered and conversations lasted a mean of 14 minutes each (range: 1 to $120 \mathrm{~min}$; IQR 8, 17).

\section{COVID-19 Screening}

Only 114 patients (3\%) reported having any symptoms associated with COVID-19 (Table 2).

\section{Medical Needs}

In total, 1,550 (48\%) patients had at least one healthcare need that required action (Table 2). Among these 1,550 patients, there was a range from one to five connections made per person, with a mean of 1.4 healthcare referrals made per person (Table 3).

One quarter of patients $(n=799,25 \%)$ reported running low on medications (Table 2) and 264 (8\%) reported running low on medical supplies, especially diabetic supplies (e.g., test strips $(n=124)$, lancets $(n=57)$, pen needles $(n=39))$.

Based on needs elicited during calls, students facilitated medication refills and shipment through a direct line to the pharmacy $(n=582,17 \%)$, referred to or three-way-called Grady's Nurse Advice Line $(n=550,16 \%)$, contacted the

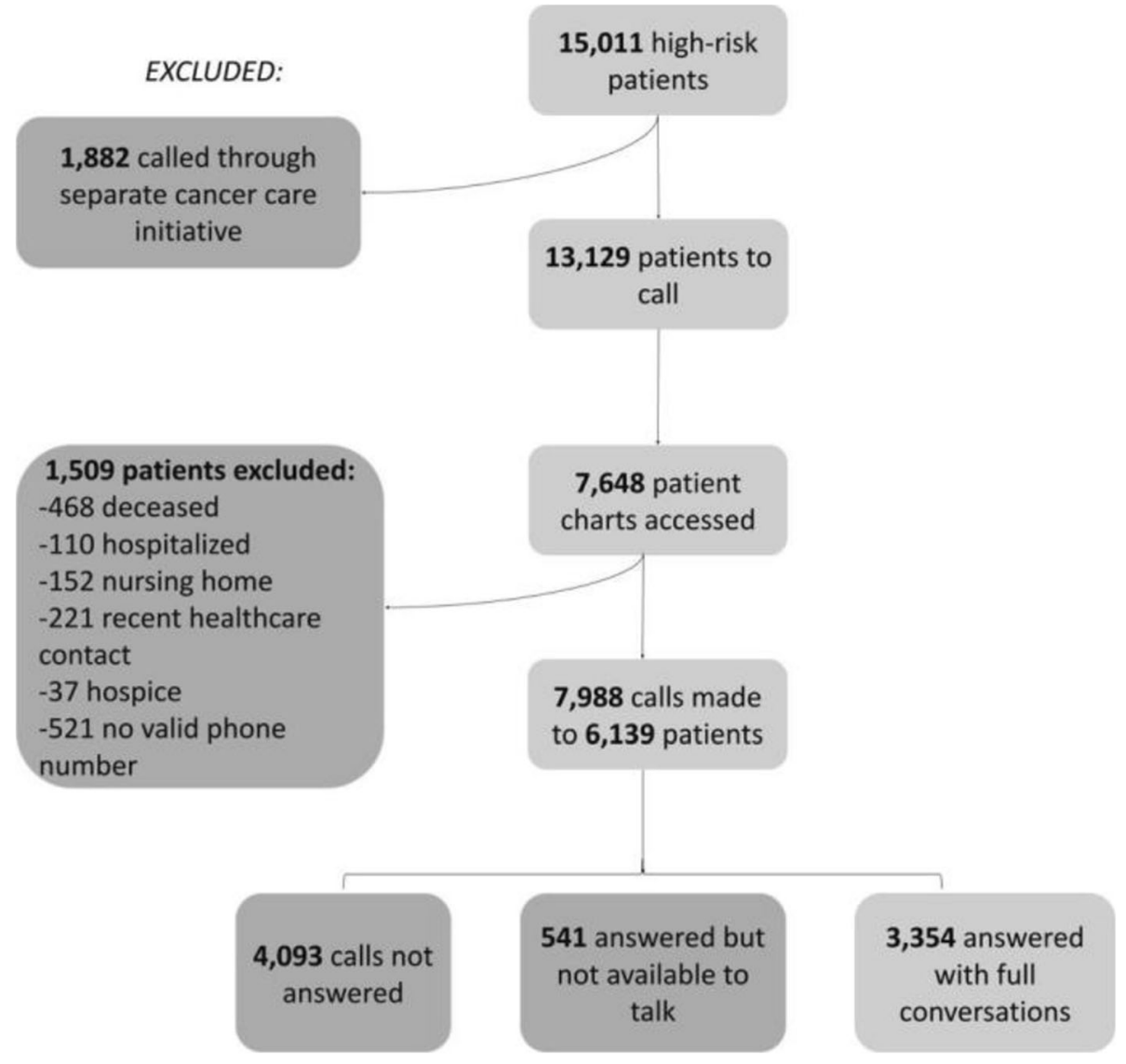

Figure 2 Number of outreach calls made to eligible patients 
Table 2 Call outcomes: health screening, social effects, and patient needs

\begin{tabular}{|c|c|}
\hline & $n(\%)$ \\
\hline \multicolumn{2}{|l|}{ Phone calls made } \\
\hline Total attempted calls to patients & 7,988 \\
\hline Total patients reached/conversations had & 3,354 \\
\hline Median calls attempted per student, $\mathrm{n}$ (IQR) & $30(18,41)$ \\
\hline \multicolumn{2}{|l|}{ Health screening and needs } \\
\hline COVID-19 screening positive for any symptom & $114(3 \%)$ \\
\hline Anxiety or mood symptoms & $307(10 \%)$ \\
\hline Running low on medications & $799(25 \%)$ \\
\hline Running low on medical supplies & $264(8 \%)$ \\
\hline $\begin{array}{l}\text { Patients requiring at least one healthcare } \\
\text { connection/referral }\end{array}$ & $1,550(48 \%)$ \\
\hline Pharmacy (Grady Pharmacy or outside) & $582(17 \%)$ \\
\hline Grady nurse advice line & $550(16 \%)$ \\
\hline $\begin{array}{l}\text { Contacted patient's provider (note routed or } \\
\text { sent Epic message) }\end{array}$ & $450(13 \%)$ \\
\hline COVID-19 vaccine support & $322(10 \%)$ \\
\hline Healthcare visit (telehealth or in-person) & $248(7 \%)$ \\
\hline Georgia Crisis and Access Line & $37(1 \%)$ \\
\hline Other mental health resource & $62(2 \%)$ \\
\hline Other medical- 911, mobile unit, etc. & $23(1 \%)$ \\
\hline Enrolled in MyChart (patient portal) & $260(59 \%)$ \\
\hline \multicolumn{2}{|l|}{ Social effects } \\
\hline Are physical distancing & $2,921(92 \%)$ \\
\hline $\begin{array}{l}\text { Someone in household still goes to work outside } \\
\text { home }\end{array}$ & $1,014(33 \%)$ \\
\hline $\begin{array}{l}\text { Did not go to ED in the last few months because } \\
\text { was worried about COVID-19 }\end{array}$ & $181(6 \%)$ \\
\hline \multicolumn{2}{|l|}{ Social needs } \\
\hline Does not have enough food & $640(20 \%)$ \\
\hline Grocery shopping/ getting food support needed & $269(8 \%)$ \\
\hline Transportation support needed & $144(4 \%)$ \\
\hline Utility assistance needed & $126(4 \%)$ \\
\hline Rent assistance needed & $114(3 \%)$ \\
\hline Stable housing needed & $55(2 \%)$ \\
\hline Internet access needed & $30(1 \%)$ \\
\hline Housekeeping support needed & $29(1 \%)$ \\
\hline Job assistance needed & $20(1 \%)$ \\
\hline $\begin{array}{l}\text { Other social support needed (e.g., home health } \\
\text { needs, childcare, educating children, etc.) }\end{array}$ & $94(3 \%)$ \\
\hline $\begin{array}{l}\text { Patients requiring at least one social connection/ } \\
\text { referral }\end{array}$ & $540(16 \%)$ \\
\hline Food-related resources & $304(9 \%)$ \\
\hline Food bank & $260(8 \%)$ \\
\hline Supplemental Nutrition Assistance & $80(2 \%)$ \\
\hline $\begin{array}{l}\text { Program (SNAP) } \\
\text { Other food service }\end{array}$ & \\
\hline $\begin{array}{l}\text { Other food service } \\
\text { United Way }\end{array}$ & $37(1 \%)$ \\
\hline United Way & $194(6 \%)$ \\
\hline FindHelp.Org (formerly Aunt Bertha) & $143(4 \%)$ \\
\hline Other (e.g., transportation, utilities, voting, etc.) & $174(5 \%)$ \\
\hline \multicolumn{2}{|l|}{ Total needs and referrals/connections } \\
\hline $\begin{array}{l}\text { Total number of connections/referrals made } \\
\text { (healthcare and social) }\end{array}$ & 3,152 \\
\hline $\begin{array}{l}\text { Total patients for whom any referrals (healthcare } \\
\text { and/or social) were made }\end{array}$ & $1,739(53 \%)$ \\
\hline
\end{tabular}

Note: \% denominators are question-specific

Table 3 Type and number of referrals/connections made for patients

\begin{tabular}{llll}
\hline \hline $\begin{array}{l}\text { Referral/ } \\
\text { connection } \\
\text { type }\end{array}$ & $\begin{array}{l}\text { Number of } \\
\text { patients } \\
\text { requiring } \\
\text { referrals/ } \\
\text { connections }\end{array}$ & $\begin{array}{l}\text { Mean number } \\
\text { of referrals/ } \\
\text { connections } \\
\text { per patient }\end{array}$ & $\begin{array}{l}\text { Range of } \\
\text { referrals/ } \\
\text { connections } \\
\text { per patient }\end{array}$ \\
\hline $\begin{array}{l}\text { Healthcare } \\
\text { Social }\end{array}$ & 1,550 & 1.4 & 1 to 5 \\
$\begin{array}{l}\text { Any } \\
\text { (healthcare }\end{array}$ & 1,739 & 1.7 & 1 to 6 \\
and/or social) & & 1.8 & 1 to 9 \\
\hline
\end{tabular}

patient's provider for follow-up $(n=450,13 \%)$ either by routing the note to the primary care provider $(n=409,13 \%)$ and/or sending an Epic message to a member of the patient's care team $(n=62,2 \%)$, requested telehealth or in-person healthcare visits $(n=248,7 \%)$, called $911(n=2)$, and deployed a mobile health unit $(n=1)$. Many patients $(n=307,10 \%)$ expressed anxiety or mood difficulties, of which $82 \%(n=252)$ completed the PHQ2. The 80 patients scoring $\geq 3$ on the PHQ2 completed the PHQ9, and 93 patients $(3 \%)$ were referred for mental health services, including 37 patients $(1 \%)$ who were offered a three-way call or given the phone number to the Georgia Crisis and Access Line for acute support (example in Fig. 3). Many of those asked $(n=181,6 \%)$ said that they would have gone to the Emergency Department (ED) recently but chose not to because they were concerned about COVID-19. To support Grady's increased use of telehealth, students enrolled 260 patients in MyChart.

\section{Social Needs}

Five hundred forty patients $(16 \%)$ had social needs that required action. Among these 540 patients, there was a range from one to six social connections made per person, with a mean of 1.7 referrals per person (Table 3 ).

One in five patients asked $(n=640,20 \%)$ reported not having enough food at home, and 269 (8\%) reported needing help grocery shopping or getting food. Accordingly, 304 patients (9\%) were connected to a food-related resource, including 260 patients $(8 \%)$ who were referred to a food bank and $80(2 \%)$ who were referred to or assisted in applying for food stamps during the call.

Other social needs included transportation challenges $(n=144,4 \%)$, utility assistance $(n=126,4 \%)$, rent assistance $(n=114,3 \%)$, stable housing $(n=55,2 \%)$, internet access $(n=30,1 \%)$, housekeeping assistance $(n=29,1 \%)$, job assistance $(n=20,1 \%)$, and other needs $(n=94,3 \%)$. In response, students made 194 connections to United Way's 2-1-1 texting platform, 143 uses of/referrals to the social needs network FindHelp. Org ${ }^{20}$ for zip code-specific resources, and 174 referrals to other resources, including local assistance centers, churches, and the Aging \& Disability Resource Center. ${ }^{21}$

Patients overwhelmingly stated that they were physically distancing (e.g., staying home and away from other people; $n=2,921,92 \%)$. However, one-third ( $n=1,014,34 \%)$ reported that someone in their household leaves the home for work. Nearly all patients asked $(n=2,311,98 \%)$ had a facemask to wear. Masks and hand sanitizer were mailed to the remaining $2 \%$ in need.

This initiative has continued after students re-entered hospital training and patients began to resume their daily lives. Emory and Morehouse have incorporated this intervention into medical school curricula by (1) ensuring all third-year medical students conduct these calls through the required Adult Primary Care clerkship (beginning July 2020), and (2) developing a for-credit elective through which students 


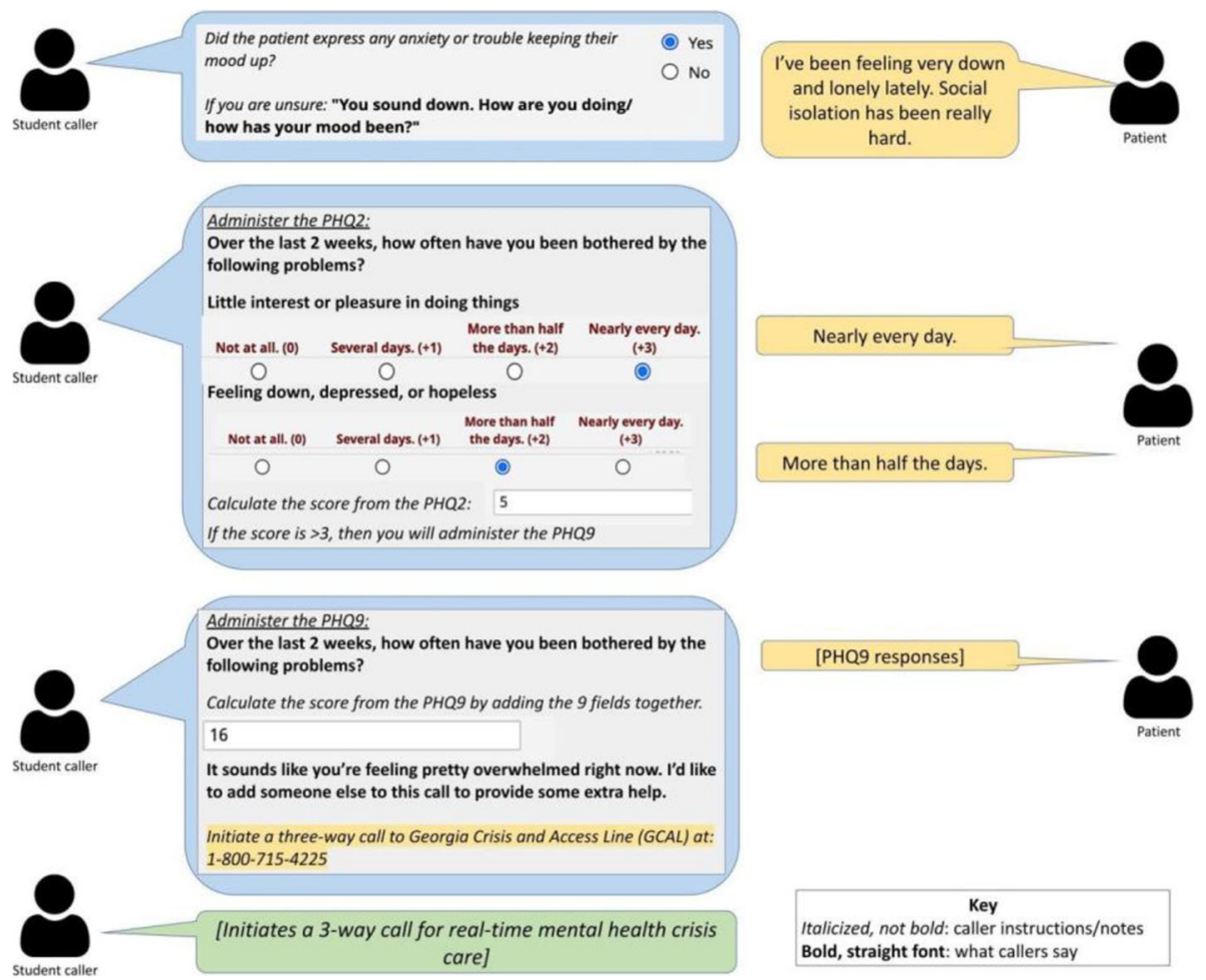

Figure 3 Excerpt of telephone conversation between a student caller and patient. The REDCap script prompts the caller to take specific action to address a mental health need

practically learn about health systems science (beginning May 2020). ${ }^{22}$

\section{DISCUSSION}

This novel initiative leveraged health professional students and technology to fill a new and pressing healthcare system gap as a result of COVID-19 by comprehensively identifying and meeting the clinical and social needs of Atlanta's patients at highest risk who were left without their normal access to healthcare.

\section{Necessity of This Intervention: Filling Gaps for Patients at High Risk}

The rapidly changing healthcare landscape during COVID-19 left patients at highest risk vulnerable to increased risk for exacerbations of their chronic conditions and with fewer familiar places to turn. Though gaps in their care existed prior to COVID-19, some chronic disease and mental health conditions may have worsened during the pandemic. ${ }^{23}$ Not surprisingly, 181 patients reported recently avoiding the ED because of COVID-19 fears when they otherwise would have gone. ${ }^{24}$ By providing a new contact for patients, students elucidated and responded to growing unmet needs at home.

\section{Impact for Patients}

Students provided necessary health and social connections for over half of the patients reached. Although these patients were part of a high-risk population often requiring many medications and frequent healthcare contact, we were struck by the high prevalence of gaps identified during these proactive calls, many of which otherwise may have gone unaddressed. Our tailored social services resource guide-encompassing COVID-19-specific and general resources - proved essential and will continue to be useful beyond the pandemic's end.

The majority of patients were seniors who are at particular risk of loneliness and isolation through COVID-19. ${ }^{25,26}$ Through these calls, patients in social isolation connected with another person safely. One patient stated that receiving our call "reminded [her] that [she was] still in this world."

Finally, our initiative also presented an opportunity for patients to ask questions about the pandemic and receive reminders about best practices to mitigate the risk of contracting and spreading COVID-19. As many lacked critical knowledge surrounding COVID-19 $9^{27}$ and most patient education materials are above appropriate literacy levels, ${ }^{28-32}$ this opportunity helped fill a crucial gap among Atlanta's persons at highest risk for poor outcomes. It also provided a foundation on which we built accompanying programs, including offering resources for voter registration and implementing a call-back program for patients with questions about the COVID-19 vaccine.

\section{Health System Impacts}

An extension of this program's goals was to prevent avoidable hospital readmissions and ED visits. The most common medications that we helped refill were for diabetes, heart failure, 
coronary artery disease, and chronic obstructive pulmonary disease - conditions among the top causes of hospital readmissions nationally, ${ }^{33,34}$ for which proper medication use is known to reduce emergency admissions. ${ }^{35}$ This work was especially important during the pandemic, as intensive care unit (ICU) beds were limited and avoidable healthcare visits not only could increase patients' COVID-19 exposure risk but also could exhaust available hospital beds and further deplete scarce personal protective equipment.

This initiative provided Grady with data regarding patient needs to equitably guide donated funds and deploy resources during COVID-19. Future analyses will further examine patients' outcomes; we anticipate finding that this outreach reduced poor outcomes for many and offset costs to patients and the system.

\section{Benefits to Health Professional Students}

Students across four graduate programs from two different schools had their first foray into telehealth. This opportunity demonstrated practically the intersections between social needs and health outcomes, provided applied education in health systems science, ${ }^{22}$ and exemplified the importance of interdisciplinary teamwork. It brought sidelined students to the pandemic's local forefront. Future analyses will examine this program's impact on student self-efficacy in identifying and addressing social determinants of health in their practice.

\section{Using This Initiative as a Model}

The proportion of patients requiring medications, health resources, and social connections has remained consistent throughout this program, suggesting at least part of the identified need exists independently of COVID-19 among Grady's population. This type of outreach should be continued beyond the pandemic and may serve to address a high level of baseline need in this population vulnerable to poor outcomes.

This initiative has the potential to be replicable in other health systems. We developed tools that were easy for students to use in a decentralized fashion and with minimal training, yet comprehensive in breadth and response. The flexible nature of the call script allowed for organic conversations between patients and students yet maintained a structure that captured important data. As we learned from each call, we honed the script and questions, and adapted the resources. The interactive discussion board made peer and faculty support accessible to callers in real time. These elements together yielded free, flexible, and impactful outreach.

There are several limitations to this study. Data were collected primarily for program monitoring, understanding patient needs, and internal quality improvement. We iteratively improved the call script and resources offered, ensuring the efficiency, breadth, and relevance of each call. Accordingly, data from questions implemented during the initiative were collected only prospectively and do not track follow-up calls. Data were limited by low phone answering rates (49\%), potential inherent differences between those who did and did not answer the phone, and an inability to validate patient responses. Next steps include a more robust analysis of the outcomes of the referrals and connections made during these calls.

\section{CONCLUSIONS}

At a time of chaos for patients unable to access routine medical care and frustration for health professional students pulled from clinical rotations, this initiative helped Atlanta's patients at highest risk access the care and social resources they needed to stay healthy at home, and provided Grady with an opportunity to better understand and meet its patients' needs. An unplanned benefit was the interdisciplinary and comprehensive exposure to health systems sciences for students from multiple health professional programs.

While COVID-19 undoubtedly worsened the healthcare and social needs patients face, gaps in care and social determinants of health are long-standing problems. This program can serve as a model for a rapid, cost-effective, high-yield outreach to promote patient health and wellness at home both during and beyond the pandemic.

Supplementary Information The online version contains supplementary material available at https://doi.org/10.1007/s11606-02107319- $x$.

Acknowledgements: We thank the student callers for their time and dedication to Grady's patients; Jvion for the targeted list of patients to call; Mary Katherine Cheeley Pharm D, Queenie Jordan, and Charlene Turner MSW for their support for patient resources; Eva Rimler MD and Emily Herndon MD for overseeing student calls; and Georges BouobdaTsemo MD and Catherine Dragon for their partnership.

Corresponding Author: Rebecca S. Goldstein, M.P.H.; Emory University School of Medicine, Atlanta, GA, USA (e-mail: rsg95@cornell. edu).

\section{REFERENCES}

1. FINRA. State "Shelter-in-Place" and "Stay-at-Home" Orders. Financial Industry Regulatory Authority; 2020. https://www.finra.org/rules-guidance/notices/20-42

2. Atlanta Co. City of Atlanta Coronavirus Disease 2019 (COVID-19) Response. Available at https://www.atlantaga.gov/government/mayorS-office/city-of-atlanta-covid-19-response. Accessed on 15 Aug 2020.

3. MARTA. COVID-19 Personnel \& Ridership Impacts. https://itsmarta com/covid-19-public-info.aspx/MARTA-service-modifications.aspx. Published 2020. Accessed 2020.

4. Al-Jabir A, Kerwan A, Nicola M, et al. Impact of the coronavirus (COVID19) pandemic on surgical practice - Part 1. Int J Surg. 2020;79:168-179.

5. Luciani LG, Mattevi D, Cai T, Giusti G, Proietti S, Malossini G. Teleurology in the time of Covid-19 pandemic: here to stay? Urology. 2020;140:4-6.

6. Gadzinski AJ, Andino JJ, Odisho AY, Watts KL, Gore JL, Ellimoottil C. Telemedicine and eConsults for hospitalized patients During COVID-19. Urology. 2020;141:12-14.

7. Khera A, Baum SJ, Gluckman TJ, et al. Continuity of care and outpatient management for patients with and at high risk for cardiovascular disease during the COVID-19 pandemic: a scientific statement from the American Society for Preventive Cardiology. American Journal of Preventive 
Cardiology. 2020:100009. https://doi.org/10.1016/j.ajpc.2020.100009. https://pubmed.ncbi.nlm.nih.gov/32835347/.

8. Gupta R, Ghosh A, Singh AK, Misra A. Clinical considerations for patients with diabetes in times of COVID-19 epidemic. Diabetes Metab Syndr. 2020;14(3):211-212.

9. Demaio A, Jamieson J, Horn R, de Courten M, Tellier S. Non-communicable diseases in emergencies: a call to action. PLoS Curr. 2013;5. https://doi.org/ 10.1371/currents.dis.53e08b951d59ff913ab8b9bb51c4d0de

10. Important guidance for medical students on clinical rotations during the coronavirus (COVID-19) outbreak [press release]. Association of American Medical Colleges (AAMC), March 17, 2020 2020. https://www.aamc. $\mathrm{org} /$ news-insights/press-releases/important-guidance-medical-students-clinical-rotations-during-coronavirus-covid-19-outbreak. Accessed 30 Mar 2020.

11. Grady Health System. Grady Fast Facts. Available at: https://www. gradyhealth.org/wp-content/auploads/2018/07/Grady_Fast_Facts.pdf. Accessed 20 Aug 2020.

12. Jvion. Reducing Readmission and improving quality of care with Jvion. 2019. https://jvion.com/about/about-jvion/

13. Harris PA, Taylor R, Minor BL, et al. The REDCap Consortium: building an international community of software platform partners. $J$ Biomed Inform. 2020;95: 103208.

14. Harris PA, Taylor R, Thielke R, Payne J, Gonzalez N, Conde JG. Research electronic data capture (REDCap)-a metadata-driven methodology and workflow process for providing translational research informatics support. $J$ Biomed Inform. 2009:42(2):377-381.

15. Kroenke K, Spitzer RL, Williams JB. The Patient Health Questionnaire-2: validity of a two-item depression screener. Med Care. 2003;41(11):12841292.

16. Kroenke K, Spitzer RL, Williams JB. The PHQ-9: validity of a brief depression severity measure. J Gen Intern Med. 2001;16(9):606-613.

17. AAFP. Social Needs Screening Tool. In: Project TE, ed: American Academy of Family Physicians 2018. https://www.aafp.org/dam/AAFP/documents/patient_care/everyone_project/hops19-physician-formsdoh.pdf. Accessed on 17 Dec 2020

18. Doximity. In. Vol Apple iOS. San Francisco, CA: Doximity; 2011. https:// www.doximity.com/. Accessed on 15 Aug 2020. Version 14.13.0.69368.0.

19. Georgia Crisis and Access Line (GCAL). In. Reston, VA: Beacon Health Options; 2020. https://www.georgiacollaborative.com/providers/georgia-crisis-andaccess-line-gcal/. Accessed August 15, 2020.

20. Aunt Bertha- The Social Care Network. Aunt Bertha, a Public Benefit Corp; 2020. Available at: https://www.auntbertha.com/. Accessed 15 Aug 2020.

21. ADRC G. Georgia's Aging \& Disability Resource Connection. Available at: https://www.georgiaadrc.com/. Published 1996. Accessed 15 Aug 2020.

22. Greenhouse AR, Goldstein RS, Bradley CD, Spell NO, Spicer JO, George MR. Student-faculty co-creation of experiential learning in health systems science. Medical teacher, 1-6. Advance online publication. https://doi.org/10.1080/0142159X.2021.1994936.
23. Chudasama YV, Gillies CL, Zaccardi F, et al. Impact of COVID-19 on routine care for chronic diseases: a global survey of views from healthcare professionals. Diabetes Metab Syndr. 2020;14(5):965-967.

24. Rehman Khalid MO, Zaheer R. The invisible victims - Impact of the pandemic on patients without COVID-19. J Pak Med Assoc. 2020;70(Suppl 3-5):S149-s152.

25. Tyrrell CJ, Williams KN. The paradox of social distancing: Implications for older adults in the context of COVID-19. Psychol Trauma. 2020;12(S1):S214-s216.

26. Malone ML, Hogan TM, Perry A, Biese K, Bonner A, Pagel P, Unroe KT. COVID-19 in Older Adults: Key Points for Emergency Department Providers. Journal of Geriatric Emergency Medicine. 2020;1(4). Retrieved from https://www.acep.org/globalassets/sites/geda/documnets/jgemcovid-19-in-older-adults.pdf.

27. Wolf MS, Serper M, Opsasnick L, et al. Awareness, attitudes, and actions related to COVID-19 among adults with chronic conditions at the onset of the U.S. outbreak: a cross-sectional survey. Ann Intern Med. 2020;173(2): 100-109.

28. Huang G, Fang CH, Agarwal N, Bhagat N, Eloy JA, Langer PD. Assessment of online patient education materials from major ophthalmologic associations. JAMA Ophthalmol. 2015;133(4):449-454.

29. Eltorai AE, Han A, Truntzer J, Daniels AH. Readability of patient education materials on the American Orthopaedic Society for Sports Medicine website. Phys Sportsmed. 2014;42(4):125-130.

30. Kher A, Johnson S, Griffith R. Readability assessment of online patient education material on congestive heart failure. Adv Prev Med. 2017;2017:9780317.

31. Smith K, Buchanan P, McDonald P. How easy is it for a lay audience to read medical journals? A survey of the readability scores of a sample of research papers on diabetes. The Lancet. 2017;390:S82.

32. Castro-Sánchez E, Spanoudakis E, Holmes AH. Readability of ebola information on websites of public health agencies, United States, United Kingdom, Canada, Australia, and Europe. Emerg Infect Dis. 2015;21(7):1217-1219.

33. HCUP Facts and Figures: Statistics on Hospital-Based Care in the United States, 2009. Healthcare Cost and Utilization Project (HCUP). Found at: https://www.ncbi.nlm.nih.gov/books/NBK91985/.

34. Jackson SL, Tong X, King RJ, Loustalot F, Hong Y, Ritchey MD. National burden of heart failure events in the United States, 2006 to 2014. Circ Heart Fail. 2018;11(12):e004873.

35. Bobrovitz N, Heneghan C, Onakpoya I, et al. Medications that reduce emergency hospital admissions: an overview of systematic reviews and prioritisation of treatments. BMC Med. 2018;16(1):115.

Publisher's Note: Springer Nature remains neutral with regard to jurisdictional claims in published maps and institutional affiliations. 